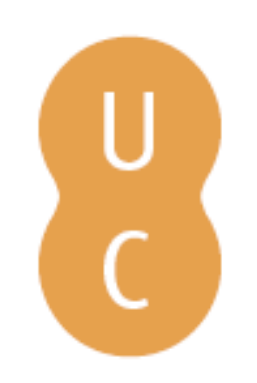

\title{
pompalina
}

\section{Tecnologias geoespaciais na demarcação da fronteira da Guiné-Bissau}
Autor(es):
Nunes, Maria do Carmo; Costa, Fernando Lagos; Melo, Ana Raquel; Morgado, Ana Maria

Publicado por: Imprensa da Universidade de Coimbra

URL

persistente:

URI:http://hdl.handle.net/10316.2/37126

DOI:

DOI:http://dx.doi.org/10.14195/978-989-26-0983-6_51

Accessed : $\quad$ 26-Apr-2023 10:58:22

A navegação consulta e descarregamento dos títulos inseridos nas Bibliotecas Digitais UC Digitalis, UC Pombalina e UC Impactum, pressupõem a aceitação plena e sem reservas dos Termos e Condições de Uso destas Bibliotecas Digitais, disponíveis em https://digitalis.uc.pt/pt-pt/termos.

Conforme exposto nos referidos Termos e Condições de Uso, o descarregamento de títulos de acesso restrito requer uma licença válida de autorização devendo o utilizador aceder ao(s) documento(s) a partir de um endereço de IP da instituição detentora da supramencionada licença.

Ao utilizador é apenas permitido o descarregamento para uso pessoal, pelo que o emprego do(s) título(s) descarregado(s) para outro fim, designadamente comercial, carece de autorização do respetivo autor ou editor da obra.

Na medida em que todas as obras da UC Digitalis se encontram protegidas pelo Código do Direito de Autor e Direitos Conexos e demais legislação aplicável, toda a cópia, parcial ou total, deste documento, nos casos em que é legalmente admitida, deverá conter ou fazer-se acompanhar por este aviso. 


\section{$\forall$ \\ TAS DAS I JORNADAS LUSÓFONAS DE CIÊNCIAS E TECNOLOGIAS DE INFORMAÇÃO GEOGRÁFICA}

Editores

José Gomes dos Santos

Cidália Fonte

Rui Ferreira de Figueiredo

Alberto Cardoso

Gil Gonçalves

José Paulo Almeida

Sara Baptista 


\section{ARTIGO 51}

\section{TECNOLOGIAS GEOESPACIAIS NA DEMARCAÇÃO}

\section{DA FRONTEIRA DA GUINÉ-BISSAU}

NUNES, Maria do Carmo; COSTA, Fernando Lagos; MELO, Ana Raquel \& MORGADO, Ana Maria

Instituto de Investigação Científica Tropical (Portugal); Travessa do Conde da Ribeira, 9B, $1^{\circ}$, $1300-142$ Lisboa, Portugal; Tel: +351 213 616340; email: mcarmonunes15@gmail.com; flcosta1955@gmail.com; a.raquel.melo@gmail.com; anammorgado@gmail.com

\section{RESUMO}

A demarcação das fronteiras africanas é uma questão em aberto, sobretudo, por dificuldade de acesso à informação sobre a sua delimitação. Por razões históricas, o Instituto de Investigação Científica Tropical (IICT) concentra um vasto acervo sobre fronteiras da CPLP, incluindo informação histórica e dados geográficos, em cadernetas de campo, croquis e cartografia de precisão. Delegações oficiais têm consultado essa documentação pelo que se considerou importante desenvolver um projeto $^{1}$ para implementar um Sistema de Informação Geográfica de Fronteiras (BGIS - Boundary Geographical Information System), para organizar a documentação e investigar metodologias visando a localização precisa dos marcos e da linha de fronteira.

${ }^{1}$ Projeto financiado pela Fundação para a Ciência e Tecnologia: PTDC/ATP-GEO/4645/2012, GEOBOUND - Tecnologias Geoespaciais na Demarcação e Gestão da Fronteira da GuinéBissau / Geospatial Tools on Demarcation and Management of Guinea Bissau Boundary. 
Apresentam-se os resultados preliminares deste projeto, sobre a fronteira da Guiné-Bissau, território onde ocorreram disputas sobre os limites da fronteira, sobretudo por desconhecimento da posição de marcos. O recurso a tecnologias geoespaciais como deteção remota, posicionamento por satélite e a trabalhos de campo, permitirá a reconstituição da linha de fronteira, no BGIS, essencial para uma fidedigna caracterização, monitorização e gestão da fronteira.

\title{
PALAVRAS-CHAVE
}

Fronteira, SIG, Deteção remota, GNSS/GPS, Guiné-Bissau.

\section{GEOSPATIAL TECHNOLOGIES ON DEMARCATION OF GUINEA BISSAU BOUNDARY}

\begin{abstract}
The demarcation of African boundaries still continues to be an unresolved issue, essentially to difficulty accessing information of its delimitation. For historical reasons, the Tropical Research Institute (IICT) concentrates a vast collection of information on the borderlands of the CPLP countries, which comprises historical documents and spatial data, included in field notebooks, sketches and mapping accuracy. Many official delegations have checked the documentation, therefore it was considered important to carry out a project to implement a Boundary Geographic Information System (BGIS), to organize boundary documents and to investigate methodologies for the accurate location of the boundary beacons and the borderline.

We present the preliminary results of this project, on the Guinea-Bissau border, a territory where boundary disputes occurred, especially due to the unknown position of the beacons. The use of geospatial technologies such as remote sensing, satellite positioning and fieldwork, will allow the reconstruction of the boundary, in a BGIS, essential for an accurate characterization, monitoring and management of the boundary.
\end{abstract}

\section{KEYWORDS}

Boundary, GIS, Remote sensing, GNSS/GPS, Guinea-Bissau.

\section{INTRODUÇÃo}

Muitas das fronteiras em África são consideradas como artificiais, por uma grande maioria de autores, pois não seguem elementos geográficos naturais, não contemplam as formas de organização política e social dos 
seus povos, nem a sua distribuição étnica. África é considerada o continente mais dividido pois é constituído por 55 estados e 109 fronteiras internacionais e tem o mais baixo ratio entre o comprimento das linhas de fronteira e a área territorial. Apenas 26\% das fronteiras africanas seguem formas de relevo (montanhas, linhas de água ou de cumeada, limites de bacias hidrográficas) e as restantes correspondem a linhas geométricas, parte das quais definidas segundo meridianos ou paralelos (Amaral, 1995).

Em África, no tempo pré-colonial, havia a noção de territorialidade e de fronteira separando entidades políticas, que eram definidas por vários fatores como o sistema político e económico ou a proporção entre a terra e a população, e não dependiam de unidades étnicas, culturais ou linguísticas, sendo por isso espaços que englobavam várias etnias e diversas línguas. No período colonial a Partilha da África foi basicamente definida após a Conferência de Berlim de 1884/85, por acordos bilaterais entre as potências administrantes para delimitação e demarcação das fronteiras, tendo sido a maioria concluída nas duas décadas seguintes.

Os limites fronteiriços, do período colonial, foram assumidos pelos novos Estados independentes, tendo-se mantido uma certa tradição africana pré-colonial de espaços políticos plurilinguísticos e multiétnicos (Döpcke, 1999). Apesar disso, muitos autores consideram que os novos países africanos adotaram o modelo europeu de estado nação e acabaram por englobar sociedades pluriculturais e multiétnicas dentro das fronteiras coloniais artificiais (Amaral, 1994). Em África existem 834 grupos etnolinguísticos, de entre os quais 358 se encontram distribuídos por mais de um país (Murdock, 1959; Michalopoulos \& Papaioannou, 2011).

A elevada percentagem de fonteiras segundo linhas retas, bem como a divisão de áreas culturais, podem sugerir uma política de desrespeito pelas realidades pré-coloniais na delimitação das fronteiras. Döpcke (1999) considera, no entanto, que existem fortes indícios de que as potências colonizadoras entraram em linha de conta com algumas das realidades sociais pré-existentes para definir as fronteiras de África e de que os dirigentes africanos locais influenciaram, em parte, o seu traçado. Admite mesmo que existem casos de correspondência entre os limites coloniais e a orientação das divisões políticas anteriores, pois muitos dos 
espaços de jurisdição de chefes africanos, referidos em tratados entre os representantes dos estados europeus e aqueles dirigentes locais, foram mantidos pelas potências coloniais europeias.

Uma grande parte dos investigadores que se dedicaram ao estudo das fronteiras em África admite, no entanto, que o traçado das fronteiras coloniais constitui um importante elemento gerador de conflitos, entre os estados africanos, ou mesmo dentro deles, constituindo um dos principais fatores de instabilidade política. Contrariamente Döpcke (1999) afirma que os conflitos armados em África ocorreram sobretudo a nível interno, dos próprios países, e a maioria das disputas fronteiriças entre 1958 e 1995, em torno de 25 casos, não envolveu violência e foi resolvida por mútuo acordo.

A linha de fronteira da Guiné-Bissau separa alguns espaços étnicos entre os países vizinhos, como os balantas, fulas e mandingas no troço norte da fronteira e os fulas no leste. A fronteira não constitui, no entanto, uma barreira aos movimentos de população e às suas atividades quotidianas, como é o caso particular do setor norte, com o Senegal, onde há grandes afinidades étnico-linguísticas entre os povos dos dois países.

A Guiné-Bissau é um país multiétnico e plurilinguístico, aspetos que têm contribuído, pelo menos em parte, para condicionar a unidade nacional e a estabilidade do país, apesar da coexistência pacífica entre as diversas etnias. Trata-se, apesar disso, de um pequeno país com uma história de algumas disputas fronteiriças, pelo que delegações oficiais têm vindo consultar a documentação da sua fronteira, existente no IICT, de modo a esclarecer questões particulares sobre alguns troços.

\section{ENQUADRAMENTO HISTÓRICO E GEOGRÁFICO}

A Guiné-Bissau, localizada na costa ocidental de África, faz fronteira com o Senegal a norte, na região de Casamança, numa extensão de cerca de $338 \mathrm{~km}$, segundo a direção predominante este-oeste. No seu troço mais oriental foi definido por um paralelo enquanto no ocidental, por uma linha a meia distância entre os rios Cacheu na Guiné-Bissau e o Casamança no Senegal, até ao litoral norte, na região do Cabo Roxo (figura 1). 
A fronteira com a Guiné-Conacri, a leste e a sudeste, estende-se por cerca de $386 \mathrm{~km}$, tendo uma orientação geral norte-sul, no setor leste, e uma disposição conjunta nordeste-sudoeste, no troço sudeste. A sua demarcação foi definida pelos talvegues do Rio Corubal e seus afluentes, e nalguns troços por linhas retas e pelo talvegue do Rio Cajete, no setor com cerca de $9 \mathrm{~km}$, mais próximo do litoral (figura 1).

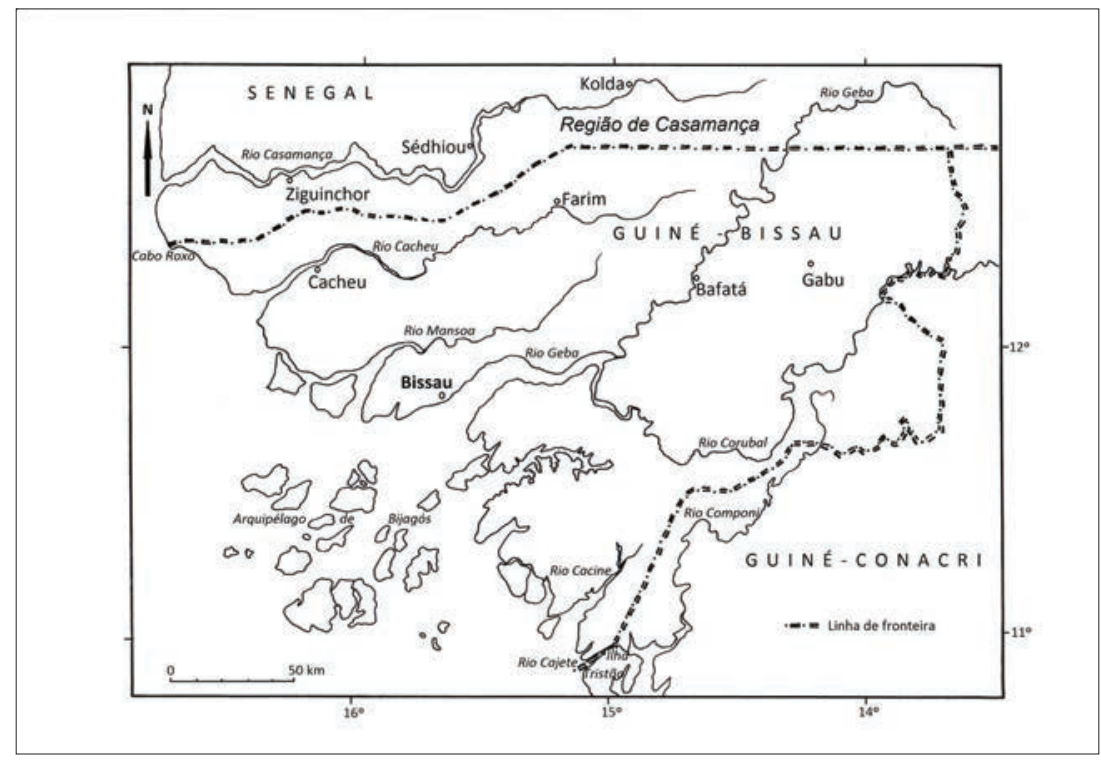

Figura 1 - Localização da Guiné-Bissau

A fronteira da Guiné-Bissau foi delimitada na sequência da "Convenção relativa à delimitação das possessões portuguesas e francesas na África Ocidental", concluída e assinada em Paris a 12 de Maio de 1886 e ratificada em Lisboa a 31 de Agosto do mesmo ano. No artigo I dessa Convenção a fronteira foi delimitada da seguinte forma: “a) ao Norte, uma linha que, partindo do Cabo Roxo se conservará [...] a igual distância dos rios de Casamansa (Cazamance) e de São Domingos de Cacheu (San-Domingo de Cacheu) até à intersecção do meridiano de $17^{\circ} 30^{\prime}$ de longitude Oeste de Paris com o paralelo de $12^{\circ} 40^{\prime}$ de latitude Norte. Entre este ponto e o meridiano de $16^{\circ}$ de longitude Oeste de Paris a fronteira confundir-se-á com o paralelo de $12^{\circ} 40^{\prime}$ de latitude Norte; b) a Leste, a fronteira seguirá 
o meridiano de $16^{\circ}$ de longitude Oeste de Paris, desde o paralelo de $12^{\circ}$ $40^{\prime}$ de latitude Norte até ao paralelo de $11^{\circ} 40^{\prime}$ de latitude Norte; c) ao Sul, a fronteira seguirá uma linha que partindo da foz do rio Cajé, situado entre a ilha Catack (atribuída a Portugal) e a ilha Tristão (atribuída a França) e, conservando-se [...] a igual distância do rio Componi (Tabatí) e do rio Cassini, [...] terminando no ponto de intersecção do meridiano de $16^{\circ}$ de longitude Oeste de Paris com o paralelo de $11^{\circ} 40^{\prime}$ de latitude Norte. Ficaram pertencendo a Portugal todas as ilhas compreendidas entre o meridiano de Cabo Roxo, a costa e um limite meridional formado por uma linha que segue o thalveg do rio Cajet dirigindo-se depois para Sudoeste, seguindo o canal dos Pilotos até atingir o paralelo de $10^{\circ} 40^{\prime}$ de latitude Norte [...] até ao meridiano de Cabo Roxo".

Em 1887 foi nomeada uma Comissão de Limites que tinha como objetivo o reconhecimento de campo para a execução da Convenção de 1886 . Os trabalhos levados a cabo pela Comissão em 1887/1888 foram iniciados no sul, a partir da Ponta Cajete (Catcheque), progredindo daí para norte, até à região de Dandum (Dandong), no limite leste, correspondente ao meridiano 160 oeste de Paris.

Na Tabela 1 apresenta-se uma síntese cronológica dos principais tratados, campanhas de levantamentos e de demarcação da fronteira da Guiné-Bissau, e ainda da cartografia produzida a nível de todo o país e da fronteira, na sequência daquela Convenção. Esta síntese foi baseada nos documentos existentes no IICT sobre a fronteira da Guiné-Bissau (1890 a 1965).

Entre 1901 e 1905 decorreram várias campanhas para demarcar com alguma precisão a fronteira, numa extensão total de aproximadamente $724 \mathrm{~km}$, com a implantação de 184 marcos primários (Tabela 1). A linha de fronteira foi materializada no terreno por uma pista de três metros de largura e por marcos de cimento, sobretudo na fronteira norte (figura 2.a), e por marcos de pedra solta, principalmente nos troços leste e sudeste da fronteira.

A demarcação desta fronteira foi um dos primeiros trabalhos levados a cabo na África de expressão portuguesa. A aprovação final dos limites sudeste e leste, com a atual Guiné-Conacri, foi realizada em 1904 e o 
acordo sobre o limite norte, com o atual Senegal, foi concretizado em 1906, entre Portugal e França, com base nos limites estabelecidos num mapa na escala de 1:250 000 .

Tabela 1 - Campanhas de demarcação da fronteira e cartografia da Guiné-Bissau

\begin{tabular}{|c|c|}
\hline Data & Campanhas / Informação Geográfica \\
\hline 1886 & $\begin{array}{l}\text { Convenção relativa à delimitação das possessões por- } \\
\text { tuguesas e francesas na África Ocidental. }\end{array}$ \\
\hline $1887-1888$ & Campanhas de reconhecimento de campo. \\
\hline $1901-1902$ & $\begin{array}{l}\text { Campanhas de demarcação da fronteira sul da Ponta } \\
\text { Cajete ao marco } 24 \text { (marcos de pedra solta). }\end{array}$ \\
\hline 1902 & $\begin{array}{l}\text { Carta da Guiné Portuguesa na escala de 1:1 } \\
000000 \text { (Lith. C. Nal. Editor, 1902). }\end{array}$ \\
\hline 1903 & $\begin{array}{l}\text { Campanha de demarcação da fronteira sul oriental, leste e nor- } \\
\text { te oriental dos marcos } 24 \text { a } 66 \text { (marcos de pedra solta). }\end{array}$ \\
\hline $1904-1905$ & $\begin{array}{l}\text { Campanhas de levantamentos da margem direi- } \\
\text { ta do Rio Cacheu e da esquerda do Casamança (fronteira } \\
\text { norte) e construção de marcos de cimento. }\end{array}$ \\
\hline 1906 & $\begin{array}{l}\text { Carta na escala de } 1: 250000 \text { com a linha de de- } \\
\text { marcação da fronteira norte dos marcos } 66 \text { a } 184 \\
\text { (da região de Pirada ao litoral) em } 2 \text { folhas. }\end{array}$ \\
\hline 1906 & Acordo final entre Portugal e França de demarcação da fronteira. \\
\hline 1906 & $\begin{array}{l}\text { Esboço da Carta da Província da Guiné na es- } \\
\text { cala de 1:500 } 000 \text { (CC/IICT, 1906). }\end{array}$ \\
\hline 1919 & $\begin{array}{l}\text { Carta na escala de } 1: 250000 \text { de delimita- } \\
\text { ção da fronteira da Guiné em } 3 \text { folhas. }\end{array}$ \\
\hline 1925 & $\begin{array}{l}\text { Campanha de verificação da fronteira da Guiné. Edificação } \\
\text { de } 6 \text { marcos intercalares na fronteira sul entre os marcos } 1 \text { e } \\
2 \text { e revisão da fronteira norte entre os marcos } 66 \text { e } 184 .\end{array}$ \\
\hline $1928-1929$ & $\begin{array}{l}\text { Campanhas de retificação da fronteira da Guiné. Determinação de } \\
\text { latitude e longitude de alguns marcos com Teodolito (Zilhão, 1930a). }\end{array}$ \\
\hline 1929 & Carta de retificação de fronteiras da Guiné na escala de 1:100 000. \\
\hline $1929-1930$ & $\begin{array}{l}\text { Campanhas de verificação da fronteira da Guiné. Determinação de } \\
\text { latitude e longitude de alguns marcos com Teodolito (Zilhão, 1930b). }\end{array}$ \\
\hline 1930 & Carta de fronteiras da Guiné na escala de 1:200 000. \\
\hline $1930-1931$ & $\begin{array}{l}\text { Campanhas de retificação da fronteira da Guiné. Determinação de } \\
\text { latitude e longitude de alguns marcos com Teodolito (Zilhão, 1932). }\end{array}$ \\
\hline 1931 & Carta da Fronteira da Guiné na escala de 1:250 000. \\
\hline 1933 & Carta da Colónia da Guiné na escala de 1:500 000 (CC/IICT, 1933). \\
\hline $1944-1954$ & Campanhas de geodesia da Guiné. \\
\hline $1949-1955$ & Fotografia aérea da Aviação Naval. \\
\hline $1950-1965$ & $\begin{array}{l}\text { Carta da Guiné Portuguesa na escala de 1:50 } 000 \text { (com localiza- } \\
\text { ção de todos os marcos de fronteira) (JMGIU/IICT, 1950-1965). }\end{array}$ \\
\hline 1961 & $\begin{array}{l}\text { Carta da Província da Guiné na escala de 1:500 } 000 \text { (com lo- } \\
\text { calização de todos os marcos de fronteira) (JIU/IICT, 1961). }\end{array}$ \\
\hline
\end{tabular}


De 1925 a 1931 decorreram várias missões de verificação e retificação da fronteira, durante as quais se fizeram observações astronómicas, com teodolito (figura 2.b), em alguns marcos, permitindo obter as coordenadas geográficas com uma maior precisão. Foram ainda reconstruídos marcos que se encontravam em mau estado e outros tiveram que ser edificados de raiz, porque os inicialmente existentes eram de pedra solta e tinham sido destruídos.
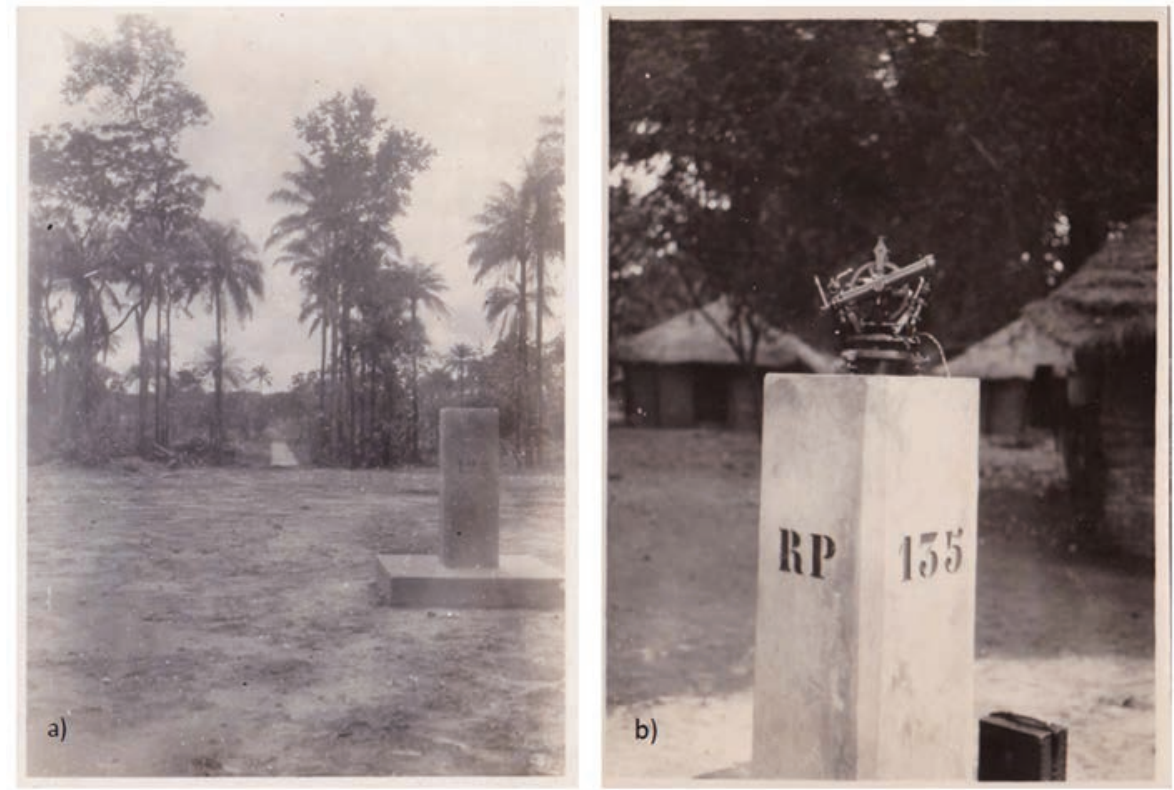

Figura 2 - Demarcação da fronteira: a) corredor de fronteira entre os marcos 127 e 128; b) marco 135 com teodolito Otto Fennel (Zilhão, 1930a)

No período de 1944 a 1955 foram realizadas campanhas geo-hidrográficas, no âmbito das quais alguns dos marcos de fronteira constituíram vértices da rede de triangulação geodésica, pelo que a sua localização foi obtida com elevada precisão.

Muitos trabalhos científicos foram efetuados sobre as fronteiras de África, no entanto foram escassos os que trataram os países de expressão portuguesa. Braz (1943) e Almeida (1994) estudaram do ponto de vista histórico a delimitação e demarcação de todas as ex-colónias portuguesas, em geral, incluindo a da Guiné-Bissau. A nível de cada país 
efectuaram-se estudos geográficos das fronteiras de Angola (Amaral, 1980) e análises históricas das fronteiras de Moçambique (Correia, 2010; Roque, 2010). Relativamente à Guiné-Bissau foi efectuado um relatório inédito (Guimarães, 1965) e publicado um livro onde se descreveram os fatos históricos, os acordos diplomáticos, os incidentes ocorridos e as fases de delimitação e demarcação da fronteira (Esteves, 1988). Nunes et al. (2012a, 2012b), apresentaram os primeiros resultados do estudo geográfico e histórico sobre a fronteira da Guiné-Bissau, recorrendo a tecnologias geoespaciais.

O primeiro mapa da Guiné-Bissau foi publicado em 1886 (Débuissons, 1886) (figura 3), onde a fronteira se encontra definida de uma forma muito grosseira e que serviu de base à Convenção internacional de 12 de Maio de 1886, entre Portugal e França as potências coloniais administrantes. Entre 1901 e 1905, na sequência das várias campanhas de demarcação foram produzidos mapas com a localização dos respetivos marcos, o mesmo sucedendo após as campanhas de verificação e retificação da fronteira de 1928 a 1931 (Tabela 1).

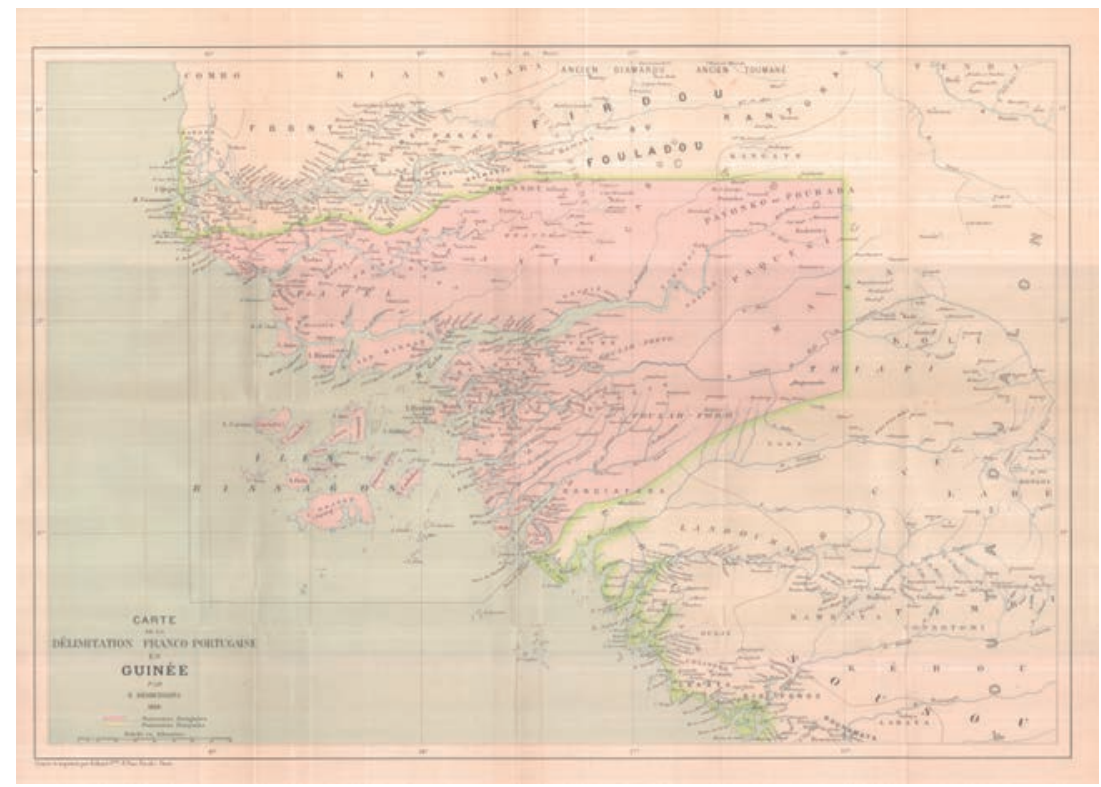

Figura 3 - Mapa de delimitação da fronteira da Guiné-Bissau (anexo I da Convenção) (Désbuissons, 1886) 
Em 1902 foi publicado um mapa do país na escala de 1:1000 000 e em 1906 e 1933 edições do mapa na escala de 1:500 000, pela Comissão de Cartografia (CC), atual IICT, onde se delimitou, com a precisão da época, a linha de fronteira (CC/IICT, 1906; CC/IICT, 1933). Entre 1950 e 1965, na sequência dos levantamentos geodésicos e da cobertura de fotografia aérea, foi editada uma carta da Guiné-Bissau, na escala de 1:50 000, com 72 folhas, produzida por restituição aerofotogramétrica, onde se incluíram todos os marcos de fronteira (JMGIU/IICT, 1950-1965). Em 1961, foi publicado um mapa geral, na escala de 1:500 000 (figura 4), onde também se encontram representados todos os marcos (JIU/IICT, 1961).

O IICT por razões históricas é detentor da documentação sobre a fronteira da Guiné-Bissau, que inclui relatórios detalhados de missões de demarcação, informação geodésica, cartografia a diversas escalas e fotografia aérea. Como instituição portuguesa, mais antiga, que se dedica à investigação científica tropical, em particular da Comunidade de Países de Língua Portuguesa (CPLP), tem vindo a disponibilizar digitalmente a vasta documentação de que dispõe.



Figura 4 - Carta da Província da Guiné. 1:500 000 (JIU/IICT, 1961) 
À semelhança do que se verificou em África, em geral, e na GuinéBissau, a maioria dos problemas de fronteira territorial surgiu pelas incongruências resultantes do pouco detalhe na descrição da linha de fronteira. São referidas naqueles documentos várias questões que advêm da pequena escala da cartografia ou das discrepâncias nos textos dos tratados. As demarcações no terreno podem também estar na origem desses problemas quando não refletem a delimitação acordada entre as partes, pela destruição da localização dos marcos, ou ainda pela ocorrência de deslocações causadas por fatores naturais, tal como a alteração do talvegue de um curso de água, que serve de linha de fronteira.

As tecnologias geoespaciais, nomeadamente as imagens de satélite e os sistemas de posicionamento global por satélite associadas com as ferramentas de SIG, têm vindo a ser utilizados na demarcação e revisão de fronteiras (Adler, 2001; Adler, 2002, Sutisna, 2010), permitindo de forma mais precisa e expedita, a produção, sobreposição, manipulação e análise deste tipo de informação geográfica.

É neste contexto que se integra o projeto "Tecnologias Geoespaciais na Demarcação e Gestão da Fronteira da Guiné-Bissau - GEOBOUND”, levado a cabo com o objetivo de dar início à criação de um Sistema de Informação Geográfica de Fronteiras (BGIS), de alguns dos países da CPLP.

\section{METODOLOGIAS E RESULTADOS}

No âmbito do projeto GEOBOUND pretende-se investigar e explorar metodologias e técnicas inovadoras para organizar e obter um BGIS, para a Guiné-Bissau. O objetivo principal é processar a informação geográfica e histórico-documental, das fronteiras terrestres e marítimas, numa perspetiva multidisciplinar e integrada e cruzar esta informação no BGIS. Implementa-se, assim, um instrumento de apoio ao ordenamento e caracterização do território, que permita um fácil acesso a informação fidedigna e devidamente organizada, a transferir para as autoridades locais competentes. Esta abordagem permite a análise dos problemas de fronteira, tirando vantagem das potencialidades das atuais tecnologias e de dados geoespaciais, como imagens de satélite recentes, de alta resolução, fotografias aéreas antigas, Sistema de Navegação Global por Satélite (Global Navigation Satellite System - GNSS), contribuindo para 
uma análise mais célere e rigorosa a utilizar na gestão da fronteira.

Como primeira tarefa procedeu-se à digitalização e processamento da documentação sobre a fronteira, arquivada numa base de dados. Foram analisados os melhores formatos e métodos de digitalização e processamento da informação, tendo o cuidado de preservar os documentos históricos e geográficos, alguns deles do século XIX, de forma a minimizar os estragos causados pelo processo de manuseamento e de digitalização.

As imagens obtidas da digitalização dos documentos históricos foram sujeitas a métodos de análise de imagem, aplicando algoritmos de morfologia matemática e outros, de remoção de ruído, eliminação de manchas de humidade, de sombreados por utilização de frente e verso da folha de papel (figura 5.a), ou ainda de sublinhados (figura 5.b). Estas técnicas permitiram também o reconhecimento de carateres, por métodos automáticos, desenvolvendo e aplicando software de OCR (Optical Character Recognition), para conversão de parte desta informação para formato texto.

Encontra-se, também, em elaboração a Base de Dados documental do acervo de fronteiras, que inclui os textos processados, com a identificação e classificação da informação histórica e geográfica e com um breve resumo dos conteúdos associados, para posterior pesquisa científica.


Figura 5 - Documentos a submeter a análise de imagem: a) utilização frente e verso; b) sublinhados e manuscritos

Paralelamente, tem sido implementado o BGIS, que integra diversos tipos de informação, geodésica e cartográfica, incluída em relatórios das Missões Geográficas, constante do arquivo de fronteiras e de publica- 
ções do IICT. Foi efetuada a georreferenciação da cartografia de base e da fotografia aérea para um mesmo sistema de coordenadas, de forma a sobrepor esta informação. Na figura 6, apresenta-se a sobreposição da cartografia de base, produzida na escala 1:500 000, com a localização dos marcos, bem como a tabela da base de dados, com a descrição da fronteira entre marcos, do troço sudeste da fronteira, na região da Ponta Cajete.

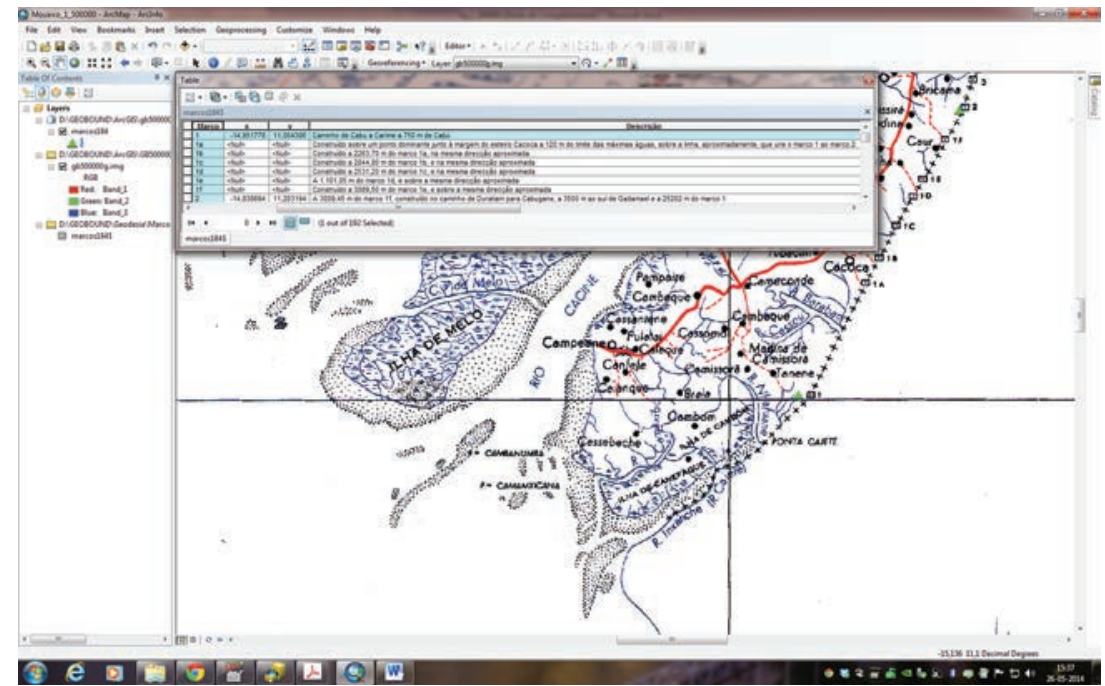

Figura 6 - BGIS do sector da Ponta Cajete entre os marcos 1 e 2 (tabela com a descrição do traçado da fronteira e mapa na escala de 1:500 000 (JIU/IICT, 1961))

A cartografia nas escalas de 1:500 000 e 1:50 000 foi produzida no sistema de coordenadas local (datum Bissau). Atualmente utilizam-se os sistemas globais de posicionamento, como o datum ITRF2008 (International Terrestrial Reference System) ou o WGS84, no qual vêm georreferenciadas as imagens de satélite. Os sistemas globais permitem, de uma forma expedita, obter coordenadas mais precisas, pelo que se considerou ser uma mais-valia proceder a trabalhos de campo, tendo como objetivo re-observar alguns marcos de fronteira e da rede geodésica, recorrendo ao uso do GNSS/GPS, para a conversão da informação geográfica existente para um datum global e produzir, assim, um BGIS mais preciso e consistente.

Outra das atividades em curso é o estudo da fronteira nos casos em 
que esta é definida pelos talvegues de cursos de água, sujeitos à evolução natural, como no estuário do Rio Cajete, no troço sudeste da fronteira (Figura 7), onde é possível efetuar estudos multitemporais recorrendo à cartografia (Figuras 7.a e b), fotografia aérea antiga e a imagens de satélite recentes (Figuras 7.c e d).
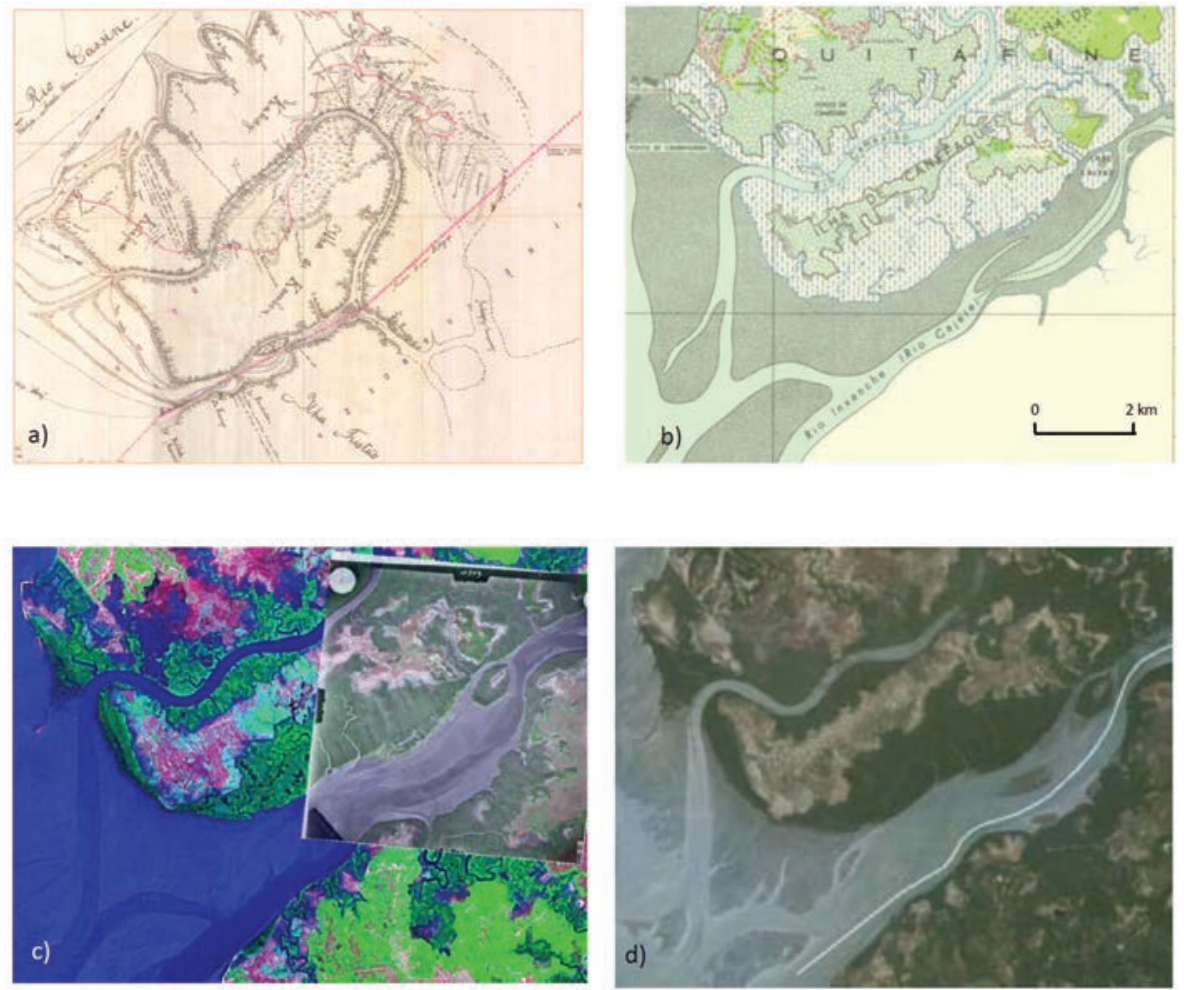

Figura 7 - Região da Ponta Cajete: a) Fronteira sul em 1897; b) Carta da Guiné, escala 1:50 000, folha de Cassumba, 1963; c) Imagem de satélite Landsat, 2000 e fotografia aérea de 1953; d) Imagem de satélite, Google (CNES/SPOT, 2014)

Os primeiros resultados deste estudo multitemporal, sobre aquele estuário, onde a dinâmica flúvio-marinha é ativa, refere-se ao período entre 1953 e 2014 e revelam algumas diferenças no que diz respeito à posição do talvegue do Rio Cajete e da área arenosa no fundo do seu vale (Figura 7). 


\section{DiSCUSSÃo E CONCLUSÕES}

A informação geográfica com o traçado da fronteira, integrada no BGIS, torna-se de fácil visualização, sobreposição e atualização, constituindo um instrumento de caracterização, monitorização e gestão do território. Esta informação, combinada com imagens de satélite de alta resolução ou do Google Earth, permite mais facilmente a localização no campo da linha de fronteira e a comparação com as atuais formas da superfície terrestre, contribuindo para uma melhor e mais rápida resolução de problemas fronteiriços, constituindo um instrumento de estabilidade regional.

Este projeto piloto será um protótipo, que poderá ser aplicado a outros países, proporcionando uma importante ferramenta, que preserva e organiza informação fundamental em suporte digital. Permite, ainda, explorar as tecnologias de posicionamento por GNSS, para produzir e validar a localização precisa dos marcos e limites fronteiriços, integrando informação de grande disparidade.

Esta abordagem multidisciplinar de delimitação das fronteiras, recorrendo a tecnologia geoespacial avançada e a metodologias inovadoras, terá um produto final que será um contributo importante para o desenvolvimento da Guiné-Bissau, e que contribui igualmente para o cumprimento do 8o Objetivo do Milénio - Desenvolvimento de uma Parceria Global para o Desenvolvimento.

\section{AgRAdeCIMENTOS}

Este trabalho é financiado por Fundos FEDER através do Programa Operacional Fatores de Competitividade - COMPETE e por Fundos Nacionais através da FCT - Fundação para a Ciência e a Tecnologia no âmbito do projeto PTDC/ATP-GEO/4645/2012, GEOBOUND - Tecnologias Geoespaciais na Demarcação e Gestão da Fronteira da Guiné-Bissau.

Agradece-se a colaboração das instituições parceiras da Guiné-Bissau, o Instituto Nacional de Estudos e Pesquisa (INEP), a Secretaria de Estado do Ambiente e Turismo (SEAT-GB) da Direção Geral do Ambiente e a Direção Geral de Geografia e Cadastro (DGGC) do Ministério das Obras Públicas Construções e Urbanismo. 


\section{BIBLIOGRAFIA}

ADLER, Ron (2001) - "Geographical Information in Delimitation, Demarcation and Management of International Land Boundaries", Boundary and Territory Briefing. Vol. 3, $\mathrm{N}^{\circ}$. 4, 78 p.. Disponível online no endereço url: https:// www.dur.ac.uk/ibru/publications/view/?id=219 (acedido em 26 de agosto de 2014).

ADLER, Ron (2002) - "Surveyors Role in Delineation and Demarcation of International Land Boundaries”. FIG XXII International Congress, Washington, D.C. USA, 13 p. Disponível online no endereço url: https://www.fig.net/ pub/fig_2002/Js20/JS20_adler.pdf (acedido em 26 de agosto de 2014).

ALMEIDA, Adelino (1994) - "A Partilha de África no Século XIX e a Definição dos Limites dos Territórios Portugueses”. Africana, Vol. 8, Nº.2, 67-82.

AMARAL, Ilídio (1980) - "Entre o Cunene e o Cubango, ou a Propósito de uma Fronteira Africana”. Lisboa, Garcia de Orta. Série de Geografia, Vol. 6 No 1-2, 1-50.

AMARAL, Ilídio (1994) - "New Reflexions on the Theme of International Boundaries", in: Schofield, Clive (ed). Global boundaries. World boundaries. Vol. 1. Londres e Nova Iorque, Routledge, 16-23.

AMARAL, Ilídio (1995) - "A África no Limiar do Século XXI: um Continente em Crise”. In: Enciclopédia Luso-Brasileira de Cultura Verbo, Vol. 23, Lisboa, Editorial Verbo, 387-418.

BRAZ, Moura (1943) - Fronteiras do Território Nacional no Ultramar. Divisão de Publicações e Biblioteca - Agência Geral das Colónias, Lisboa: Editorial Ática. 156 p..

CC/IICT (1906) - Esboço da Carta da Província da Guiné. Escala 1:500 000. Lisboa, Comissão de Cartografia / Instituto de Investigação Científica Tropical.

CC/IICT (1933) - Carta da Colónia da Guiné. Escala 1:500 000. Lisboa, Comissão de Cartografia / Instituto de Investigação Científica Tropical.

CORREIA, Milton (2010) - Norte de Moçambique, 1886-1918: Soberania, Dominação e Administração Coloniais. Dissertação de Mestrado em Educação/Ensino de História, Universidade Pedagógica, 78 p. Disponível online no endereço url: www.saber.ac.mz/bitstream/10857/3593/1/NorteMoçambique.pdf (acedido em 07 agosto, 2014).

DÉSBUISSONS, Louis (1886) - Carte de la Délimitation Franco-Portugaise de la Guinée. Escala 1:1 000 000. Paris, Erhard F..

DÖPCKE, Wolfgang (1999) - "A Vida Longa das Linhas Retas: Cinco Mitos Sobre as Fronteiras na África Negra”. Revista Brasileira de Política Internacional, Vol.42, $\mathrm{N}^{\circ} .1,77-109$. Disponível online no endereço url: http://pt.scribd. com/doc/52967155/HG-Cinco-mitos-sobre-as-fronteiras-da-Africa (acedido 
em 14 de maio de 2014).

ESTEVES, Maria (1988) - A Questão do Casamança e a Delimitação das Fronteiras da Guiné. Lisboa, Instituto de Investigação Científica Tropical e Instituto Nacional de Estudos e Pesquisa, Lisboa, 310 p.

GUimARÃeS, Maria (1965) - Fronteira da Guiné. Sinopse. Lisboa, Centro de Geografia do Ultramar, Junta de Investigações do Ultramar, 36 p. (não publicado).

JIU/IICT (1961) - Carta da Província da Guiné. Escala 1:500 000. Lisboa, Centro de Geografia do Ultramar, Junta de Investigações do Ultramar / Instituto de Investigação Científica Tropical.

JMGIU/IICT (1950-1965) - Guiné Portuguesa. Escala 1:50 000. Lisboa, Junta de Missões Geográficas e Investigações do Ultramar / Instituto de Investigação Científica Tropical.

MICHALOPOULOS, Stelios \& PAPAIOANNOU, Elias (2011) - The Long-Run Effects of the Scramble for Africa. National Bureau of Economic Research, Working Paper 17620, 72 p. Disponível online no endereço url: http://www.yale. edu/leitner/resources/papers/scramble_africa_stelios_elias.pdf (acedido em 26 de agosto de 2014).

MURDOCK, George (1959) - Africa: Its Peoples and their Culture History. McGraw Hill, New York, 456 p. Disponível online no endereço url: http://peterslarson.com/2011/01/19/african-conflict-and-ethnic-distribution/ (acedido em 16 de maio de 2012).

NUNES, Maria \& MORGADO, Ana (2012a) - "O SIG na Delimitação da Fronteira da Guiné-Bissau”. Livro de resumos do Colóquio Internacional Ciência nos Trópicos: Olhares Sobre o Passado, Perspectivas de Futuro. Instituto de Investigação Científica Tropical, Lisboa, 36. Disponível online no endereço url: www2.iict.pt/archive/doc/Livro_Resumos_Coloquio_IICT.pdf (acedido em 07 agosto de 2014).

NUNES, Maria; MORGADO, Ana \& COSTA, Fernando (2012b) - "Digital Delimitation of Guinea Bissau Terrestrial Boundaries". In Borders and Borderlands 2012. Proceedings of Today's Challenges and Tomorow's Prospects, Lisboa, 223-237.

ROQUE, Ana (2010) - "Sources for the History of Southern Border of Mozambique: Preliminary Results of a Project on Archives of the Portuguese Commission of Cartography". Journal of Borderlands Studies, Vol. 25, No. 2, 77-93.

SUTISNA, Sobar (2010) - "International Boundary Fixing and the Roles of Indonesian Surveyors." In International Boundary Issues, FIG Congress 2010, Facing the Challenges - Building the Capacity. Sydney, Australia, 7 p. Disponível online no endereço url: http://www.fig.net/pub/fig2010/papers/ts02a/ ts02a_sutisna_3888.pdf (acedido em 26 de agosto de 2014). 
Atas das I Jornadas Lusófonas de Ciências e Tecnologias de Informação Geográfica, Sessão 12, Artigo 51

ZILHÃO, João (1930a) - Missão de Rectificação de Fronteiras da Guiné. Campanha de 1928-1929. Relatório. Lisboa, s/ ed., 69 p. (não publicado)

ZILHÃO, João (1930b) - Missão de Fronteiras da Guiné. Campanha de 1929-1930. Relatório. Lisboa, s/ ed., 46 p. (não publicado).

ZILHÃO, João (1932) - Missão de Rectificação de Fronteiras da Guiné. Campanha de 1930-1931. Relatório. Lisboa, s/ ed., 31 p. (não publicado) 
Série Documentos

Imprensa da Universidade de Coimbra

Coimbra University Press

2015

- U M

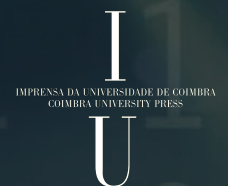

